COLORECTAL CANCER

\title{
Birth size and colorectal cancer risk: a prospective population based study
}

T I L Nilsen, P R Romundstad, R Troisi, N Potischman, L J Vatten

Gut 2005;54:1728-1732. doi: 10.1136/gut.2004.060475

See end of article for authors' affiliations ......................

Correspondence to: Professor L J Vatten Department of Public Health and General Practice, The Norwegian University of Science and Technology, NO-7489 Trondheim, Norway; lars.vatten@ medisin.ntnu.no

Revised version received 7 April 2005 Accepted for publication 12 April 2005 Published online first 20 April 2005

\begin{abstract}
Objective: To study whether birth size influences colorectal cancer risk in adulthood.
Design: A cohort of Norwegian men and women identified from midwives' birth records with long term cancer follow up through the Norwegian Cancer Registry.

Setting: St Olav's University Hospital, Trondheim, Norway.

Participants: 16016 women and 19681 men born between 1920 and 1958 and alive in 1960 .

Outcome measures: Incidence rate ratios (RRs) for colorectal cancer with $95 \%$ confidence intervals (Cls) and two sided $p$ values for trend across categories of birth dimensions.

Results: Men whose birth length was less than $51 \mathrm{~cm}$ had a nearly twofold higher risk of colorectal cancer (RR 1.9 (95\% Cl 1.0-3.7)) compared with men who were $53 \mathrm{~cm}$ or more, after adjustment for birth cohort, maternal age at childbearing, length of gestation, gestational hypertension or pre-eclampsia, birth order, maternal height, and indicators of maternal socioeconomic status. The association displayed a linear trend across categories of birth length $\left(p_{\text {trend }}=0.03\right.$ ). Among men, similar associations were found for birth weight and head circumference, but for women there was no association between any of these birth dimensions and risk of colorectal cancer.

Conclusion: The results suggest that among men, but not women, being relatively short at birth is associated with increased risk of colorectal cancer in adulthood, indicating that intrauterine growth could be important for colorectal carcinogenesis.
\end{abstract}

$\mathrm{R}$ elatively small birth size has been associated with a higher risk of cardiovascular disease and diabetes in men $^{12}$ and lower risk of breast cancer in women..$^{3-6}$ One previous study has examined the risk of colorectal cancer related to birth dimensions and found a J-shaped association with self reported birth weight. ${ }^{7}$ It has been hypothesised that associations between perinatal factors and adult diseases may be attributed to intrauterine alterations in pregnancy hormones (that is, growth hormones, steroid hormones, insulin) that in turn lead to persistent changes in organ structure or function. ${ }^{89}$ Several studies have shown that intrauterine growth restriction is associated with higher blood lipids in adolescence and adulthood, a greater tendency for insulin resistance and high blood pressure, and increased risk of diabetes and cardiovascular disease in adulthood..$^{10-12}$

In adulthood, colorectal cancer risk has been associated with the presence of diabetes, ${ }^{13}{ }^{14}$ hyperglycaemia, ${ }^{15}{ }^{16}$ hyperinsulinaemia, ${ }^{15}{ }^{17} 18$ and high concentrations of insulin-like growth factor I (IGF-I). ${ }^{17}$ The similarity in risk factors between type 2 diabetes and colorectal cancer has led some investigators to hypothesise that insulin may act as a tumour promoter in the development of colorectal cancer $^{1920}$ and results from experimental studies indicate that insulin promotes the growth of colon tumours. ${ }^{21}$

The evidence that metabolic aberrations related to the development of type 2 diabetes may have an intrauterine origin, and their positive associations with colorectal cancer, suggest that the long term consequences of intrauterine growth restriction may also be important for colorectal carcinogenesis.

In this study of approximately 16000 women and nearly 20000 men born between 1920 and 1958, we have prospectively studied colorectal cancer risk associated with birth size (that is, birth length, birth weight, head circumference) and other pregnancy related factors.

\section{METHODS}

\section{Material}

We abstracted information from birth records of all births that took place at St Olav's University Hospital, Trondheim, Norway, from 1920 to 1958, including a total of 21147 female and 22270 male offspring. In the records, each child birth was registered by the mother's name, offspring birth date, and the child's first name.

In 1960, every Norwegian citizen was assigned an individual 11 digit identification number, and each citizen's record was continuously updated on vital status and residential history through the national Central Person Registry, and if the ID number is known, this registry allows linkage between family members. We used information from the Central Person Registry to identify women and men who were alive in 1960 and born at St Olav's Hospital between 1920 and 1958. If the mother had died before 1960, she was not assigned the unique identification number and therefore the link between the mother and child could not be verified for all offspring, particularly for women who had changed their last name when they married. Thus among a total of 20610 female singletons, we reliably identified 16016 $(77.7 \%)$ women who could be followed up for colorectal cancer. Verification was less complicated for men, and among a total of 21703 male singletons, we reliably identified $19681(90.7 \%)$ men who could be followed up.

The reporting of cancer to the Norwegian Cancer Registry is mandatory, and colorectal cancer was registered according to the International Classification of Diseases (ICD-7, seventh revision, code 153-154). For women and men who where 20 years of age or older in 1960 (born 1920-1940), follow up for colorectal cancer started on 1 January 1961. Women and

Abbreviations: IGF, insulin-like growth factor; IGFBPs, insulin-like growth factor binding proteins; RR, rate ratio 
men born between 1941 and 1958 were followed from their 20th birthday. Follow up ended when a cancer (at any site) was diagnosed, at emigration, death, or at the end of follow up (31 December 2001), whichever occurred first.

Information on birth weight $(\mathrm{g})$, birth length $(\mathrm{cm})$, head circumference $(\mathrm{cm})$, duration of gestation (in weeks or months), pregnancy complications (that is, pre-eclampsia and hypertension), and birth order was abstracted from birth records. Furthermore, we abstracted information on maternal age, height, marital status, and socioeconomic status (occupation) at childbearing. Placental weight (g) has been measured and recorded since 1934, and we abstracted this information for participants born in 1934 or later.

\section{Statistical methods}

Birth size variables (birth weight, birth length, head circumference, and placental weight) were categorised by sex into four approximately equal categories (exact quartiles were not possible due to the discrete nature of these variables) and analysed separately for women and men.

Cox regression analysis was used to calculate incidence rate ratios (RRs) for colorectal cancer associated with each of the birth size characteristics, as well as pregnancy and maternal factors. Precision of effects was estimated using 95\% confidence intervals (CIs), and two sided $\mathrm{p}$ values from trend tests were calculated by treating categories as ordinal variables in the regression model. To adjust for cohort effects, we included birth year in five year intervals (from 1920 to 1958). In the regression analysis, we also adjusted for maternal age at childbearing $(<25,25-29,30-34, \geqslant 35$ years), preterm (length of gestation less than 37 weeks) or term birth (length of gestation 37 weeks or more), gestational hypertension and/or pre-eclampsia (no, yes), birth order (1st, 2nd, 3rd, $\geqslant 4$ th), maternal height (in approximate quartiles), and maternal socioeconomic status (manual labour versus other occupations).

\section{RESULTS}

During 41 years of follow up (median 31 years), 97 new cases of colorectal cancer were registered among women and 150 among men. Median age at diagnosis among women was 58 years (range 27-79) and 59 years (range 26-79) among men, reflecting that this cohort was still relatively young. During follow up, 1037 women and 1119 men were censored when they were diagnosed with other cancers, 480 women and 1621 men when they died from causes other than cancer, and 325 women and 451 men were censored when they emigrated and could no longer be followed.

Among men in the lowest category of birth length $(<5 \mathrm{l} \mathrm{cm})$, the risk of colorectal cancer was nearly twice as high (RR 1.9 (95\% CI 1.0-3.7)) as for men in the highest $(\geqslant 53 \mathrm{~cm})$ category, after adjustment for birth cohort, maternal age at childbearing, length of gestation, gestational hypertension or pre-eclampsia, birth order, maternal height, and indicators of maternal socioeconomic status (table 1).

The risk displayed a linear trend $\left(p_{\text {trend }}=0.03\right)$ from the highest to the lowest category of birth length. In relation to birth weight, the adjusted RR of colorectal cancer was higher for men whose birth weight was lower than the highest quartile ( $\geqslant 3925 \mathrm{~g}$ ) but the risk increase with decreasing birth weight was less consistent $\left(p_{\text {trend }}=0.20\right)$ than for birth length. For head circumference however, there was a clear increase in colorectal cancer risk with decreasing head circumference at birth $\left(\mathrm{p}_{\text {trend }}=0.04\right)$. Men in the lowest category $(<35 \mathrm{~cm})$ had an adjusted RR of 1.5 (95\% CI $0.9-$ $2.3)$ compared with men in the highest category $(\geqslant 37 \mathrm{~cm})$ of head circumference. In an additional analysis (data not shown), we mutually adjusted the effect of birth length, birth weight, and head circumference. The results showed that the association with birth length remained nearly unchanged (adjusted RR 1.8 (95\% CI 0.9-3.8), comparing lowest to highest category); the association with head circumference was slightly attenuated (adjusted RR 1.3 (95\% CI 0.7-2.3), comparing lowest to highest category); and the association with birth weight was fully attenuated (adjusted RR 1.0 (95\% CI 0.5-2.0), comparing lowest to highest category). In the subgroup of men who were born after 1933, we also had information on placental weight. The results showed a higher risk of colorectal cancer (adjusted RR 1.6 (95\% CI 1.0-2.7))

Table 1 Relative risks (RRs) and 95\% confidence interval (Cls) for colorectal cancer associated with measures of birth size among 19681 Norwegian men born between 1920 and 1958

\begin{tabular}{|c|c|c|c|c|c|}
\hline Variable & $\begin{array}{l}\text { No of } \\
\text { cases }\end{array}$ & $\begin{array}{l}\text { No of } \\
\text { men }\end{array}$ & $\mathbf{R R}^{*}$ & $\operatorname{RRT}(95 \% \mathrm{Cl})$ & $p$ Trend $\ddagger$ \\
\hline \multicolumn{6}{|l|}{ Birth weight (g) } \\
\hline$<3270$ & 47 & 4969 & 1.7 & $1.7(1.0-2.8)$ & \\
\hline $3270-3590$ & 33 & 4829 & 1.4 & $1.3(0.7-2.2)$ & \\
\hline $3595-3920$ & 46 & 5017 & 1.8 & $1.8(1.1-2.9)$ & \\
\hline$\geqslant 3925$ & 24 & 4861 & 1.0 & 1.0 (ref) & 0.20 \\
\hline \multicolumn{6}{|c|}{ Birth length $(\mathrm{cm})$} \\
\hline$<51$ & 81 & 6724 & 2.1 & $1.9(1.0-3.7)$ & \\
\hline 51 & 37 & 3715 & 2.2 & $2.1(1.1-4.1)$ & \\
\hline 52 & 20 & 4028 & 1.4 & $1.3(0.6-2.7)$ & \\
\hline$\geqslant 53$ & 12 & 5205 & 1.0 & 1.0 (ref) & 0.03 \\
\hline \multicolumn{6}{|c|}{ Head circumference $(\mathrm{cm})$} \\
\hline$<35$ & 47 & 4782 & 1.5 & $1.5(0.9-2.3)$ & \\
\hline 35 & 44 & 5092 & 1.3 & $1.2(0.8-2.0)$ & \\
\hline 36 & 30 & 5124 & 0.9 & $0.9(0.5-1.4)$ & \\
\hline$\geqslant 37$ & 29 & 4612 & 1.0 & 1.0 (ref) & 0.04 \\
\hline \multicolumn{6}{|c|}{ Placental weight§ (g) } \\
\hline$<600$ & 25 & 4361 & 1.7 & $1.6(1.0-2.7)$ & \\
\hline$\geqslant 600$ & 46 & 12609 & 1.0 & 1.0 (ref) & \\
\hline
\end{tabular}

*Adjusted for year of birth (1920-1924, 1925-1929, ..., 1955-1958).

†Adjusted for year of birth (1920-1924, 1925-1929, ..., 1955-1958), maternal age at childbearing $(<25,25-$ $29,30-34, \geq 35$ years), length of gestation (preterm ( $<37$ weeks) or term ( $\geqslant 37$ weeks)), gestational hypertension and/or pre-eclampsia (no, yes), birth order (1st, 2nd, 3rd, $\geqslant 4$ th), maternal height (quartiles), maternal marital status (married, unmarried, widow, divorced), and maternal socioeconomic status (manual labour versus other occupations).

$\ddagger$ Two sided $p$ values for trend in Cox regression.

§Information on placenta weight available since 1934 
Table 2 Relative risks (RRs) and 95\% confidence interval (Cls) for colorectal cancer associated with measures of birth size among 16016 Norwegian women born between 1920 and 1958

\begin{tabular}{|c|c|c|c|c|c|}
\hline Variable & $\begin{array}{l}\text { No of } \\
\text { cases }\end{array}$ & $\begin{array}{l}\text { No of } \\
\text { women }\end{array}$ & $\mathbf{R R}^{*}$ & $\mathrm{RR} \dagger(95 \% \mathrm{Cl})$ & p Trend $\ddagger$ \\
\hline \multicolumn{6}{|l|}{ Birth weight (g) } \\
\hline$<3150$ & 32 & 4045 & 1.2 & $1.3(0.7-2.4)$ & \\
\hline $3150-3440$ & 17 & 3956 & 0.7 & $0.7(0.4-1.4)$ & \\
\hline $3445-3760$ & 27 & 3983 & 1.1 & $1.2(0.7-2.2)$ & \\
\hline$\geqslant 3765$ & 21 & 4027 & 1.0 & 1.0 (ref) & 0.65 \\
\hline \multicolumn{6}{|l|}{ Birth length $(\mathrm{cm})$} \\
\hline$<50$ & 33 & 4095 & 0.7 & $0.7(0.4-1.3)$ & \\
\hline 50 & 28 & 3764 & 0.7 & $0.7(0.4-1.2)$ & \\
\hline 51 & 13 & 3002 & 0.6 & $0.7(0.3-1.3)$ & \\
\hline$\geqslant 52$ & 23 & 5152 & 1.0 & 1.0 (ref) & 0.33 \\
\hline \multicolumn{6}{|c|}{ Head circumference $(\mathrm{cm})$} \\
\hline$<34$ & 15 & 2660 & 0.8 & $0.9(0.5-1.7)$ & \\
\hline 34 & 26 & 3768 & 1.1 & $1.1(0.6-1.9)$ & \\
\hline 35 & 29 & 4520 & 1.0 & $1.0(0.6-1.7)$ & \\
\hline$\geqslant 36$ & 27 & 5004 & 1.0 & 1.0 (ref) & 0.89 \\
\hline \multicolumn{6}{|c|}{ Placental weight§ (g) } \\
\hline$<600$ & 14 & 4148 & 0.8 & $0.8(0.4-1.8)$ & \\
\hline$\geqslant 600$ & 36 & 10125 & 1.0 & 1.0 (ref) & \\
\hline \multicolumn{6}{|c|}{ 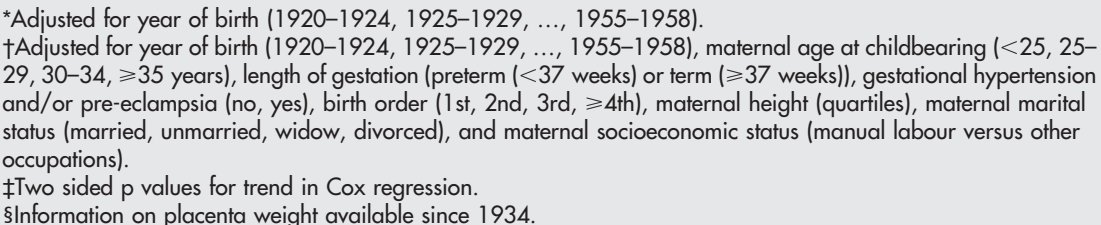 } \\
\hline
\end{tabular}

associated with a relatively small $(<600 \mathrm{~g})$ placenta compared with larger placentas ( $\geqslant 600 \mathrm{~g})$. In all of these analyses, the direction of the association was similar for colon and rectal cancer but the association was consistently stronger for colon than for rectal cancer (data not shown).

Similar analyses were performed for women, but showed no association (positive or negative) with the risk of colorectal cancer for any of the recorded perinatal factors (table 2).

Furthermore, we analysed the association between maternal factors and risk of colorectal cancer among offspring (table 3). We found that for men, but not for women, maternal age at childbearing was inversely related to colorectal cancer risk $\left(\mathrm{p}_{\text {trend }}=0.009\right)$. In men whose mothers were 35 years of age or older at childbearing, the adjusted RR was 0.6 (95\% CI 0.3-1.2) compared with men whose mothers were younger than 25 years (table 3 ).

\section{DISCUSSION}

In this prospective study of approximately 36000 Norwegian women and men, colorectal cancer risk among men was substantially higher for those who were born relatively small, as measured by birth length and head circumference. A similar association with birth weight was fully attenuated after mutual adjustment for birth length and head circumference. The increased risk related to small birth size

Table 3 Relative risks (RRs) and $95 \%$ confidence intervals (Cls) for colorectal cancer associated with maternal characteristics among 35697 Norwegian men and women born between 1920 and 1958

\begin{tabular}{|c|c|c|c|c|c|c|c|c|c|c|}
\hline \multirow[b]{2}{*}{ Variable } & \multicolumn{5}{|c|}{ Women } & \multicolumn{5}{|l|}{ Men } \\
\hline & $\begin{array}{l}\text { No of } \\
\text { cases }\end{array}$ & $\begin{array}{l}\text { No of } \\
\text { women }\end{array}$ & $\mathbf{R R}^{*}$ & $\begin{array}{l}\text { RR† } \\
(95 \% \mathrm{CI})\end{array}$ & p Trend $\ddagger$ & $\begin{array}{l}\text { No of } \\
\text { cases }\end{array}$ & $\begin{array}{l}\text { No of } \\
\text { men }\end{array}$ & $\mathbf{R R}^{*}$ & $\begin{array}{l}\text { RR† } \\
(95 \% \mathrm{CI})\end{array}$ & p Trend $\ddagger$ \\
\hline \multicolumn{11}{|c|}{ Maternal age $(y) \dagger$} \\
\hline$<25$ & 35 & 4711 & 1.0 & 1.0 & & 61 & 5789 & 1.0 & 1.0 & \\
\hline $25-29$ & 29 & 4805 & 0.9 & $0.9(0.5-1.5)$ & & 55 & 6020 & 0.9 & $0.9(0.6-1.3)$ & \\
\hline $30-34$ & 15 & 3767 & 0.6 & $0.6(0.3-1.1)$ & & 17 & 4525 & 0.4 & $0.4(0.2-0.7)$ & \\
\hline$\geqslant 35$ & 17 & 2694 & 1.0 & $1.0(0.5-2.1)$ & 0.85 & 17 & 3320 & 0.6 & $0.6(0.3-1.2)$ & 0.009 \\
\hline \multicolumn{11}{|c|}{ Maternal birth ordert } \\
\hline 1st & 46 & 7208 & 1.0 & 1.0 & & 79 & 8758 & 1.0 & 1.0 & \\
\hline 2nd & 28 & 4962 & 1.1 & $1.2(0.7-2.0)$ & & 43 & 6077 & 1.0 & $1.1(0.8-1.7)$ & \\
\hline $3 r d$ & 11 & 2278 & 0.9 & $1.1(0.5-2.2)$ & & 17 & 2806 & 0.9 & $1.1(0.6-1.9)$ & \\
\hline$\geqslant 4$ th & 12 & 1552 & 1.0 & $1.1(0.5-2.4)$ & 0.84 & 11 & 2023 & 0.5 & $0.6(0.3-1.3)$ & 0.44 \\
\hline \multicolumn{11}{|c|}{ Maternal height $(\mathrm{cm})$} \\
\hline$<1.59$ & 24 & 3477 & 1.0 & 1.0 & & 47 & 4444 & 1.0 & 1.0 & \\
\hline $1.59-1.62$ & 20 & 3869 & 1.1 & $1.1(0.6-2.1)$ & & 31 & 4777 & 0.8 & $0.8(0.5-1.3)$ & \\
\hline $1.63-1.66$ & 20 & 3795 & 1.4 & $1.4(0.8-2.6)$ & & 23 & 4454 & 0.8 & $0.8(0.5-1.4)$ & \\
\hline$\geqslant 1.67$ & 11 & 3318 & 1.1 & $1.1(0.5-2.2)$ & 0.96 & 8 & 3978 & 0.9 & $0.9(0.5-1.5)$ & 0.37 \\
\hline
\end{tabular}

*Adjusted for year of birth (1920-1924, 1925-1929, ..., 1955-1958).

†All variables in the table are mutually adjusted, in addition to adjustment for year of birth (1920-1924, 1925-1929, ..., 1955-1958), length of gestation (preterm ( $<37$ weeks) or term ( $\geqslant 37$ weeks)), gestational hypertension and/or pre-eclampsia (no, yes), maternal marital status (married, unmarried, widow, divorced), and maternal socioeconomic status (manual labour versus other occupations).

$\ddagger$ Two sided $\mathrm{p}$ values for trend in Cox regression. 
displayed a linear trend across the distribution of birth length and head circumference, and the association was particularly strong for colon cancer. For women, however, there was no association between any of the perinatal factors and colorectal cancer risk.

One previous prospective study found a J-shaped relation between birth weight and risk for colorectal cancer. ${ }^{7}$ That study was based on a few cases, and combined men and women in the analyses. We are not aware of other studies that have assessed birth size in relation to subsequent risk for colorectal cancer. It should be noted that our study cohort was still relatively young, and that future cancer follow up will allow greater precision in the estimated associations with perinatal factors. This will also allow us to study whether these associations are equally important for young and old cases of colorectal cancer. Furthermore, higher statistical power will allow more detailed analysis of the sex difference that we observed in this study.

In this study, we used birth records from the archives of St Olav's University Hospital, Trondheim, Norway, for the period 1920-1958. The proportion of total deliveries that took place in this clinic varied from approximately 50\% in 1920 to nearly $100 \%$ in 1958. The proportion of inhospital births increased gradually during the period: it was 57\% in 1930 and had reached more than $90 \%$ in 1944 . Hence the cohort included in the present study should be fairly representative of the general population in the area.

The birth records were based on information that was routinely entered onto a form that remained practically unchanged throughout the period. Some minor changes were implemented in 1934 when measurements and description of the placenta were included as routine. Moreover, midwives that worked at the clinic were almost exclusively educated at one particular school of nursing, which makes it likely that measurements of birth weight, length, and head circumference were roughly standardised throughout the period.

Another strength of our study includes the collection of perinatal information from birth records, with measured as opposed to self reported information on birth size. Among the 35697 newborns in this study for example, only 10 babies had missing data on birth weight, 12 had missing data on birth length, and 136 had missing data on head circumference.

Also, long term follow up for colorectal cancer incidence of a large and unselected population strengthens the validity of our findings. Reporting of cancer to the Cancer Registry is mandatory for all physicians in Norway, and all pathological laboratories send copies of their laboratory reports to the Cancer Registry. To achieve a high degree of completeness, the Cancer Registry is continuously matched against the Registry of Deaths. This study was based on 247 cases of colorectal cancer (97 females and 150 males), and 240 of these were histologically verified $(97.2 \%)$; only one case was based on the death certificate alone.

One possible weakness was the lack of information on other potentially confounding factors in adulthood, such as dietary factors, body mass index, and physical activity. Also, it would be preferable to have clinical information on diabetes and the presence of hyperinsulinaemia or insulin resistance in adulthood but information on these conditions is not readily available. However, the association between birth size and most of these adult factors may not be sufficiently strong to have confounded the relation between birth size and colorectal cancer risk in our study. Also, it could be argued that some of these factors may be regarded as intermediate variables on a causal pathway between intrauterine influences and colorectal cancer development, and statistical adjustment for these factors may not be appropriate.
A large number of epidemiological studies have examined perinatal characteristics and risk of cardiovascular disease, diabetes, and metabolic risk profiles (for example, blood lipid levels, insulin resistance, hypertension). According to a recent review, there is convincing evidence that low birth weight is associated with insulin resistance and other signs of metabolic disturbances that may be present already in adolescence. ${ }^{22}$ Except for breast cancer, perinatal factors have been less extensively studied in relation to cancer risk. For breast cancer, there is evidence suggesting that the risk is higher for women of relatively high compared with low birth size. ${ }^{3-6} \mathrm{~A}$ few previous studies have related perinatal factors to risk of other cancers in adulthood, such as prostate and testicular cancer, and the results have not shown any consistent pattern. ${ }^{23-26}$

That low birth weight is associated with disturbances in insulin metabolism in adulthood may be relevant to our findings among men. It has been suggested that hyperinsulinaemia increases colorectal cancer risk, ${ }^{1920}$ and recent epidemiological studies have found that diabetes ${ }^{13}{ }^{14}$ and hyperglycaemia ${ }^{15}{ }^{16}$ are associated with increased risk. One prospective study found a twofold higher risk for those who had serum insulin concentrations in the highest compared with the lowest quartile of insulin. ${ }^{15}$ Two other prospective studies reported a substantially higher risk among those who had the highest compared with the lowest insulin secretion, as indicated by serum concentrations of C peptide. ${ }^{17}{ }^{18}$ Results of studies in vivo show that insulin may promote the growth of precancerous aberrations and tumours of the colon. ${ }^{21} 2728$ Furthermore, studies in vitro suggest that insulin may increase the growth of carcinoma cells from the colon. ${ }^{29} 30$

It has also been shown that hyperinsulinaemia influences IGFs, and high circulating levels of IGF-I have been related to a higher risk of colorectal cancer. ${ }^{15}{ }^{17}$ Sustained high levels of insulin lead to reduced production of IGF binding proteins (IGFBPs) in the liver, followed by higher levels of biologically available IGF-I. ${ }^{31}$ Previously, a prospective study found that hyperinsulinaemia and relatively high levels of IGF-I were related to an increased risk of colorectal cancer whereas the binding proteins IGFBP-1 and IGFBP-2 were negatively associated with risk. ${ }^{17}$ As small birth size is related to metabolic aberrations later in life, including hyperinsulinaemia, our finding that small birth size among men is related to an increased risk of colorectal cancer may be interpreted in the context of the insulin-IGF axis.

In our study, relatively small birth size was consistently associated with a higher risk of colorectal cancer among men, but among women there was no association between birth size dimensions and subsequent risk of colorectal cancer. Other factors have also differed by sex in their relation to colorectal cancer risk. In adulthood, there has been a consistent positive association with body mass index in men, but among women there appears to be a positive association with body mass index among premenopausal but not postmenopausal women. ${ }^{32}$ Furthermore, menopausal women who use hormone replacement therapy appear to be at reduced risk of colorectal cancer. ${ }^{33}$ It has been suggested that the differences in colorectal cancer risk by sex may implicate a differential role for sex hormones, related to oestrogens in particular, ${ }^{34}$ but the actual mechanism remains obscure.

In conclusion, these results provide evidence that reduced longitudinal growth in utero may increase future risk for colorectal cancer in men. Mechanisms for such a relation may involve early metabolic aberrations that influence insulin regulation, the insulin-like growth factor system, and steroid hormones.

\section{ACKNOWLEDGEMENTS}

This work was supported by the Norwegian Cancer Society and by the Norwegian Research Council. 
TILN and PRR performed the statistical analysis and drafted the manuscript. RT and NP advised on the analyses and contributed to the writing of the paper. LJV initiated and designed the study, and contributed to the analysis and writing of the paper.

\section{Authors' affiliations}

T I L Nilsen, P R Romundstad, L J Vatten, Department of Public Health and General Practice, Faculty of Medicine, The Norwegian University of Science and Technology, Trondheim, Norway

R Troisi, Division of Cancer Epidemiology and Genetics, National Cancer Institute, National Institutes of Health, Bethesda, USA N Potischman, Division of Cancer Control and Population Sciences, National Cancer Institute, National Institutes of Health, Bethesda, USA

Conflict of interest: None declared.

\section{REFERENCES}

1 Barker DJ, Winter PD, Osmond C, et al. Weight in infancy and death from ischaemic heart disease. Lancet 1989;2:577-80.

2 Leon DA, Lithell HO, Vagero D, et al. Reduced fetal growth rate and increased risk of death from ischaemic heart disease: cohort study of 15000 Swedish men and women born 1915-29. BMJ 1998;317:241-5.

3 Ahlgren M. Sorensen T, Wohlfahrt J, et al. Birth weight and risk of breast cancer in a cohort of 106,504 women. Int J Cancer 2003;107:997-1000.

4 McCormack VA, dos SS, I, De Stavola BL, et al. Fetal growth and subsequent risk of breast cancer: results from long term follow up of Swedish cohort. BMJ 2003;326:248

5 Potischman N, Troisi R. In-utero and early life exposures in relation to risk of breast cancer. Cancer Causes Control 1999;10:561-73.

6 Vatten L, Maehle BO, Lund Nilsen TI, et al. Birth weight as a predictor of breast cancer: a case-control study in Norway. Br J Cancer 2002;86:89-91.

7 Sandhu MS, Luben R, Day NE, et al. Self-reported birth weight and subsequent risk of colorectal cancer. Cancer Epidemiol Biomarkers Prev 2002; 11:935-8

8 Barker DJ, Gluckman PD, Godfrey KM, et al. Fetal nutrition and cardiovascular disease in adult life. Lancet 1993:341:938-41.

9 Ekbom A. Growing evidence that several human cancers may originate in utero. Semin Cancer Biol 1998;8:237-44.

10 Eriksson J, Forsen T, Tuomilehto J, et al. Fetal and childhood growth and hypertension in adult life. Hypertension 2000;36:790-4

11 Eriksson JG, Forsen TJ. Childhood growth and coronary heart disease in later life. Ann Med 2002;34:157-61.

12 Forsen T, Eriksson J, Tuomilehto J, et al. The fetal and childhood growth of persons who develop type 2 diabetes. Ann Intern Med 2000;133:176-82.

13 Hu FB, Manson JE, Liu S, et al. Prospective study of adult onset diabetes mellitus (type 2) and risk of colorectal cancer in women. J Natl Cancer Inst 1999:91:542-7.

14 Will JC, Galuska DA, Vinicor F, et al. Colorectal cancer: another complication of diabetes mellitus? Am J Epidemiol 1998;147:816-25.
15 Schoen RE, Tangen CM, Kuller $\mathrm{LH}$, et al. Increased blood glucose and insulin, body size, and incident colorectal cancer. I Natl Cancer Inst 1999;91:1 147-54.

16 Yamada K, Araki S, Tamura M, et al. Relation of serum total cholesterol, serum triglycerides and fasting plasma glucose to colorectal carcinoma in situ. Int J Epidemiol 1998;27:794-8.

17 Kaaks R, Toniolo P, Akhmedkhanov A, et al. Serum C-peptide, insulin-like growth factor (IGF)-I, IGF-binding proteins, and colorectal cancer risk in women. J Natl Cancer Inst 2000;92:1592-600.

$18 \mathrm{Ma} \mathrm{J}$, Giovannucci E, Pollak M, et al. A prospective study of plasma C-peptide and colorectal cancer risk in men. J Natl Cancer Inst 2004;96:546-53.

19 Giovannucci E. Insulin and colon cancer. Cancer Causes Control 1995;6:164-79.

20 Keown-Eyssen G. Epidemiology of colorectal cancer revisited: are serum triglycerides and/or plasma glucose associated with risk? Cancer Epidemiol Biomarkers Prev 1994;3:687-95.

21 Tran Tा, Medline A, Bruce WR. Insulin promotion of colon tumors in rats. Cancer Epidemiol Biomarkers Prev 1996;5:1013-15.

22 Newsome CA, Shiell AW, Fall CH, et al. Is birth weight related to later glucose and insulin metabolism? -A systematic review. Diabetes Med 2003:20:339-48.

23 Boland LL, Mink PJ, Bushhouse SA, et al. Weight and length at birth and risk of early-onset prostate cancer (United States). Cancer Causes Control 2003; 14:335-8.

24 Ekbom A, Hsieh CC, Lipworth L, et al. Perinatal characteristics in relation to incidence of and mortality from prostate cancer. BMJ 1996;313:337-41.

25 Rasmussen F, Gunnell D, Ekbom A, et al. Birth weight, adult height, and testicular cancer: cohort study of 337,249 Swedish young men. Cancer Causes Control 2003;14:595-8.

26 Richiardi L, Askling J, Granath F, et al. Body size at birth and adulthood and the risk for germ-cell testicular cancer. Cancer Epidemiol Biomarkers Prev 2003; 12:669-73.

27 Corpet DE, Jacquinet C, Peiffer G, et al. Insulin injections promote the growth of aberrant crypt foci in the colon of rats. Nutr Cancer 1997; 27:316-20.

28 Koohestani N, Tran TT, Lee W, et al. Insulin resistance and promotion of aberrant crypt foci in the colons of rats on a high-fat diet. Nutr Cancer 1997;29:69-76.

29 Koenuma M, Yamori T, Tsuruo T. Insulin and insulin-like growth factor 1 stimulate proliferation of metastatic variants of colon carcinoma 26. Jpn J Cancer Res 1989;80:51-8.

30 Watkins LF, Lewis LR, Levine AE. Characterization of the synergistic effect of insulin and transferrin and the regulation of their receptors on a human colon carcinoma cell line. Int J Cancer 1990;45:372-5.

31 Sandhu MS, Dunger DB, Giovannucci EL. Insulin, insulin-like growth factor-I (IGF-I), IGF binding proteins, their biologic interactions, and colorectal cancer J Natl Cancer Inst 2002:94:972-80.

32 Terry PD, Miller AB, Rohan TE. Obesity and colorectal cancer risk in women. Gut 2002;51:191-4.

33 Chlebowski RT, Wactawski-Wende J, Ritenbaugh C, et al. Estrogen plus progestin and colorectal cancer in postmenopausal women. N Engl J Med 2004;350:991-1004

34 Giovannucci E. Obesity, gender, and colon cancer. Gut 2002;51:147. 